\title{
Neuropathy-Induced Apoptosis: Protective Effect of Physostigmine
}

\author{
L. Di Cesare Mannelli, ${ }^{\star}$ A. Bartolini, and C. Ghelardini \\ Department of Preclinical and Clinical Pharmacology, University of Florence, Florence, Italy
}

Traumatic, infectious, metabolic, and chemical noxa to the nervous system are the etiology of a crippling disease generally termed neuropathy. Motor disorders, altered sensibility, and pain are the pathognomonic traits. Cellular alterations induced by this chronic pathology include mitochondrial dysfunctions that lead to the activation of the apoptotic cascade. Energy imbalance can compromise the maintenance of mitochondrial membrane potential, furthering the release of cytochrome $\mathrm{C}$ and the subsequent cleavage and activation of caspases. Chronic constriction injury $(\mathrm{CCl})$ of the rat sciatic nerve is a neuropathy model able to induce a strong mitochondrial impairment with a consequent apoptotic induction. In this model, the acetylcholinesterase inhibitor physostigmine is administered at 0.125 $\mathrm{mg} / \mathrm{kg}$ i.p. (twice per day) starting from the operation and for 15 days after. The cholinergic activation reduces cytosolic levels of cytochrome $\mathrm{C}$, suggesting an improved stability of the mitochondrial membrane, and the expression level of the active caspase 3 fragments $(19,16 \mathrm{kDa})$ is reduced significantly with respect to saline treatment. Accordingly, physostigmine impairs caspase 3 protease activity. In fact, the target of the activated caspase 3 , the $89-\mathrm{kDa}$ PARP fragment, is significantly less expressed in the ligated nerve of physostigmine-treated rats, reaching levels that are comparable to those in the contralateral unligated nerve. Finally, this natural acetylcholinesterase inhibitor reduces DNA fragmentation both in the proximal and in the distal parts of the nerve. This protection correlates with the induction of XIAP. Therefore, apoptosis, central to tissue degeneration, is prevented by repeated physostigmine treatment of CCl animals. () 2009 Wiley-Liss, Inc.

Key words: AChE; XIAP; CCl; peripheral nerve; tissue degeneration

Damage to the nervous system at peripheral, spinal, or supraspinal sites can induce complex syndromes characterized by the combination of negative symptoms or sensory deficits, such as partial or complete loss of sensation, and positive symptoms that include dysesthesia, paresthesia, and pain. Neuropathic pain is characterized by areas of sensory abnormality, with sensory hypoand/or hypersensitivity. Allodynia and hyperalgesia may be the dominating clinical feature. Neuropathies and the related pain are often classified according to underlying etiology, e.g., painful diabetic neuropathy, postherpetic neuralgia, phantom limb pain, HIV neuropathy, central poststroke pain, and spinal cord injury pain. Finally, neuropathic syndromes are also common in cancer patients, secondary to direct infiltration or pressure on peripheral nerves or the central nervous system, resulting from chemotherapy or nerve injury following operation (Jensen et al., 2001; Hughes, 2002; Obrosova et al., 2002; Finnerup et al., 2007).

Pathophysiological mechanisms related to neuropathic disease are associated with mitochondrial dysfunctions that lead to activation of the apoptotic cascade. Mitochondrial membrane permeabilization causes release of cytochrome $\mathrm{C}$ and the subsequent formation of a complex that initiates cleavage and activation of caspases (Dalakas et al., 2001; Andre et al., 2002; Moulder et al., 2002; Siler-Marsiglio et al., 2004; Leinninger et al., 2006; Melli et al., 2006).

To gain insight into the relationship between neuropathy and apoptosis, we recently assessed the activation of the apoptotic pathway in rats that had undergone loose ligation of the sciatic nerve (CCI). With this peripheral neuropathy model, we described a nerve apoptotic state that encompasses the release of the cytochrome $\mathrm{C}$ in the cytosol, activation of caspase 3, and fragmentation of the genome (Di Cesare Mannelli et al., 2007). Recently, Joseph and Levine (2004) have demonstrated that apoptotic phenomena are involved in the neuropathic pain-related hyperalgesia, insofar as the inhibition of caspases $1,2,3,8$, and 9 reduced hyperalgesia in rat models of neuropathy induced by cancer or antiviral chemotherapy. On the other hand, acetyl-L-carnitine had a similar profile, showing both the antihyperalgesic and the antiapoptotic effects in the CCI model (Di Cesare Mannelli et al., 2007).

The plant-derived acetylcholinesterase (AChE) inhibitor physostigmine (also known as eserine, from éséré, a West African name for the calabar bean) is able to raise the pain threshold, showing an antihyperalgesic effect,

^Correspondence to: Lorenzo Di Cesare Mannelli, Department of Preclinical and Clinical Pharmacology, University of Florence, Viale Pieraccini 6, 50139 Florence, Italy. E-mail: lorenzo.mannelli@unifi.it

Received 3 October 2008; Revised 13 November 2008; Accepted 23 November 2008

Published online 23 January 2009 in Wiley InterScience (www. interscience.wiley.com). DOI: 10.1002/jnr.22007 
both in acute (Galeotti et al., 2003) and in chronic algic conditions (Pöyhiä et al., 1999). On the other hand, the cholinergic level enhancement has a pivotal role in neuroprotection and in the inhibitory mechanism of apoptosis (Villaroya et al., 2007; Jiang and Zhang, 2008). Moreover, the acetylcholine-hydrolyzing enzyme AChE has recently been described as being overexpressed in different cell types undergoing apoptosis induced by several agents; protein levels and both mRNA expression and stability are enhanced (Huang et al., 2005; Jiang and Zhang, 2008). To study protective profile of physostigmine in the CCI model, we evaluated the effect of repeated treatment with this natural AChE inhibitor on apoptosis.

\section{MATERIALS AND METHODS}

\section{Animals}

Male Sprague-Dawley rats from Harlan-Italia (Varese, Italy) were used. Four rats were housed per cage (size $26 \times$ $41 \mathrm{~cm})$ and placed in the experimental room for acclimatization $24 \mathrm{hr}$ before the test. The animals were fed with standard laboratory diet and with tap water ad libitum and were kept at $23^{\circ} \mathrm{C} \pm 1{ }^{\circ} \mathrm{C}$ with a 12 -hr light/dark cycle, lights on at 7 AM. All animal manipulations were carried out according to the European Community guidelines for animal care (DL 116/92, application of the European Communities Council Directive of 24 November 1986; 86/609/EEC). The ethical policy of the University of Florence conforms with the Guide for the care and use of laboratory animals of the U.S. National Institutes of Health (NIH Publication No. 85-23, revised 1996; University of Florence assurance No. A5278-01). All efforts were made to minimize animal suffering and to reduce the number of animals used.

\section{Peripheral Rat Mononeuropathy}

Neuropathy was induced according to the procedure described by Bennett and Xie (1988). Briefly, rats were anesthetized with $400 \mathrm{mg} / \mathrm{kg}$ intraperitoneal (i.p.) chloral hydrate. Under aseptic conditions, the right common sciatic nerve was exposed at the level of the middle thigh by blunt dissection. Proximal to the trifurcation, the nerve was carefully freed from the surrounding connective tissue, and four chromic cat gut ligatures (4-0; Ethicon, Norderstedt, Germany) were tied loosely around it with about $1 \mathrm{~mm}$ spacing. After hemostasis was confirmed, the incision was closed in layers. The animals were allowed to recover from surgery and then housed one per cage with free access to water and standard laboratory chow.

\section{Drug Administration}

Physostigmine (eserine), gabapentin, and chloral hydrate were purchased from Sigma (St. Louis, MO). The administration was performed intraperitoneally.

\section{Tissue Explants}

After treatment, animals were sacrificed, and the right sciatic nerves, $1 \mathrm{~cm}$ upstream the ligation and the trifurcation, were explanted. The same procedure was performed for the left, unoperated nerve. Tissue extracted was approximately 20 mg. All the experiments were performed using the entire portion of the nerve, including the ligature site, except for the nick translation labeling assay. For this assay, portions of the nerve approximately $1 \mathrm{~cm}$ upstream (proximal) and $1 \mathrm{~cm}$ downstream (distal) the ligation were processed, and the nerve fragments carrying the ligature were left out. Each experiment was performed on a single rat nerve.

\section{Western Blot}

Tissue was homogenized in lysis buffer containing 50 $\mathrm{mM}$ Tris- $\mathrm{HCl}, \mathrm{pH} 8.0,150 \mathrm{mM} \mathrm{NaCl}, 1 \mathrm{mM}$ EDTA, $0.5 \%$ Triton X-100, Complete Protease Inhibitor (Roche, Indianapolis, IN). The homogenate was incubated on ice for 30 min, and then the suspension was sonicated on ice using three $10-\mathrm{sec}$ bursts at high intensity with a $10-\mathrm{sec}$ cooling period between each burst. The samples were centrifuged at $13,000 \mathrm{~g}$ for $15 \mathrm{~min}$ at $4^{\circ} \mathrm{C}$. Protein concentrations in the supernatant were measured by bicinchoninc acid (BCA; Sigma-Aldrich Italy) assay. Thirty micrograms of each protein extract was separated on a $4-12 \%$ sodium dodecyl sulfate (SDS)-polyacrylamide gel by electrophoresis and transferred onto nitrocellulose membranes (Bio-Rad Italy). Membranes were blocked with $5 \%$ nonfat dry milk in phosphate-buffered saline (PBS) containing $0.1 \%$ Tween 20 (TPBS) and then probed overnight with primary antibodies [caspase 3, cytochrome C, poly (ADP-ribose) polymerase (PARP), and X-linked inhibitor of apoptosis protein (XIAP) antibodies (Cell Signalling, Beverly, MA); 1:1,000 in PBST/5\% milk]. After washing with PBST, the membranes were incubated for $1 \mathrm{hr}$ in PBST containing the appropriate horseradish peroxidase-conjugated secondary antibody $(1: 5,000)$ and again washed. ECL (Pierce, Rockford, IL) was used to visualize the peroxidase-coated bands. Densitometric analysis was performed in Scion Image software. $\beta$-Actin normalization was performed for each sample.

\section{Caspase 3 Enzymatic Activity}

Nerve segments (20 $\mathrm{mg}$ each) were homogenized in $200 \mathrm{mM}$ Tris-HCl buffer, $\mathrm{pH} 7.5$, containing $2 \mathrm{M} \mathrm{NaCl}, 20$ $\mathrm{mM}$ EDTA, and $0.2 \%$ Triton $\mathrm{X}-100$ and centrifuged at $5,000 \mathrm{~g}$ for $5 \mathrm{~min}$ at $4^{\circ} \mathrm{C}$. Protein concentrations in the supernatants were determined as reported in the previous section. Fifty microliters of the supernatants was incubated with 0.025 $\mathrm{mM}$ fluorogenic peptide caspase substrate $0.025 \mathrm{mM}$ rhodamine110 bis (N-CBZ-L-aspartyl-L-glutamyl-L-valyl-L-aspartic acid amide; Z-DEVD-R110; Molecular Probes, Eugene, OR) in a buffer containing $10 \mathrm{mM}$ PIPES, $\mathrm{pH}$ 7.4, $10 \mathrm{mM}$ EDTA, $0.5 \% \mathrm{CHAPS}$, at $25^{\circ} \mathrm{C}$ for $30 \mathrm{~min}$. The amount of cleaved substrate in each sample was measured in a 96-well plate fluorescent spectrometer (Perkin-Elmer, Norwalk, CT; excitation at $496 \mathrm{~nm}$ and emission at $520 \mathrm{~nm}$ ). Each experiment was performed in duplicate.

\section{Cytochrome C: cytosolic fraction extraction}

This procedure was performed as reported by Cervia and coworkers (2006), with minor modifications. Briefly, nerve tissue was homogenized in $10 \mathrm{mM}$ Tris-HCl buffer ( $\mathrm{pH}$ 7.5), 0.3 M sucrose, $1 \mathrm{mM}$ EDTA, and Complete Prote- 
ase Inhibitor (Roche). Samples were centrifuged at $10,000 \mathrm{~g}$ for $60 \mathrm{~min}$ at $4^{\circ} \mathrm{C}$, and the supernatants containing the cytosolic fraction were collected. Pellets were resuspended in a cold buffer containing $10 \mathrm{mM}$ Tris- $\mathrm{HCl}, \mathrm{pH} 7.5,150 \mathrm{mM}$ $\mathrm{NaCl}, 1 \mathrm{mM}$ EDTA, 1\% Triton X-100, and Complete Protease Inhibitor (Roche) and sonicated on ice with three 20-sec bursts at high intensity, with a $10-\mathrm{sec}$ cooling period between each burst. Supernatants containing the mitochondrial fraction were obtained by centrifugation at $10,000 \mathrm{~g}\left(30 \mathrm{~min}, 4^{\circ} \mathrm{C}\right)$. Protein concentrations were determined as reported. Western blot with cytochrome C oxidase subunit IV (COX IV) antibody was performed to verify the absence of mitochondrial contaminants in the cytosol preparation.

\section{DNA Fragmentation. Nick Translation Labeling}

Evaluation of the DNA cleavage was performed by labeling DNA strand breaks using the Klenow enzyme to attach to the biotin-tagged deoxy-nucleotiodes, as described by Gorczyca et al. (1993). Sections (7 $\mu \mathrm{m})$ obtained from paraffin-embedded sciatic nerves were rehydrated and then digested with $20 \mu \mathrm{g} / \mathrm{ml}$ proteinase $\mathrm{K}$ for $20 \mathrm{~min}$ at room temperature (RT). After being rinsed in TBS, endogenous peroxidases were inactivated with $30 \% \mathrm{H}_{2} \mathrm{O}_{2}, 1: 10$ in methanol for $5 \mathrm{~min}$ at $\mathrm{RT}$. After equilibration with a $0.5 \mathrm{M}$ Tris- $\mathrm{HCl}$ buffer, $\mathrm{pH}$ 8.0, containing $0.5 \mathrm{M} \mathrm{NaCl}, 0.1 \mathrm{M} \mathrm{MgCl}_{2}$, sections were incubated with reaction mix containing labeled and unlabeled deoxynucleotides and Klenow enzyme (Calbiochem, La Jolla, CA) at $37^{\circ} \mathrm{C}$ for $1.5 \mathrm{hr}$. Labeling reactions were stopped by incubating for 5 min with $0.5 \mathrm{M}$ EDTA, pH 8.0, at RT. Subsequently, a peroxidise-streptavidin conjugate was applied for $30 \mathrm{~min}$ at $\mathrm{RT}$, and detection was obtained by incubation with $3,3^{\prime}$-diaminobenzidine- $\mathrm{H}_{2} \mathrm{O}_{2}$ /urea solution (15 min, RT). Sections were then treated with $0.3 \%$ methyl green for $6 \mathrm{~min}$.

\section{Statistical Analysis}

Results are expressed as means \pm SEM, and an ANOVA was performed. Fisher's protected least significant difference procedure was used as post hoc comparison. $P<$ 0.01 was considered significant. Data were analyzed in Origin 7.5 software.

\section{RESULTS}

Because the complex apoptosis signalling pathway converges on caspase- 3 activation, Figure 1 shows Western blot analysis of procaspase $3(36 \mathrm{kDa})$ and its cleaved active fragment (19 and $16 \mathrm{kDa}$ ). Starting on the day of the operation, the treatment of the CCI rats with physostigmine $0.125 \mathrm{mg} / \mathrm{kg}$ intraperitoneally (i.p.) twice per day for 15 days prevented caspase 3 cleavage (Fig. 1a) in the ligated right sciatic nerve. The expression of the 19$\mathrm{kDa}$ and $16-\mathrm{kDa}$ fragments was significantly decreased in the right nerve after physostigmine treatment with respect to saline-treated rats (Fig. 1b). The effect of physostigmine administration was compared with the effect of gabapentin, an antiepileptic drug widely employed in neuropathic pain clinical management. Gabapentin at 70 $\mathrm{mg} / \mathrm{kg}$ injected i.p. twice per day for 15 days was not able to prevent caspase 3 induction (Fig. 1a,b).

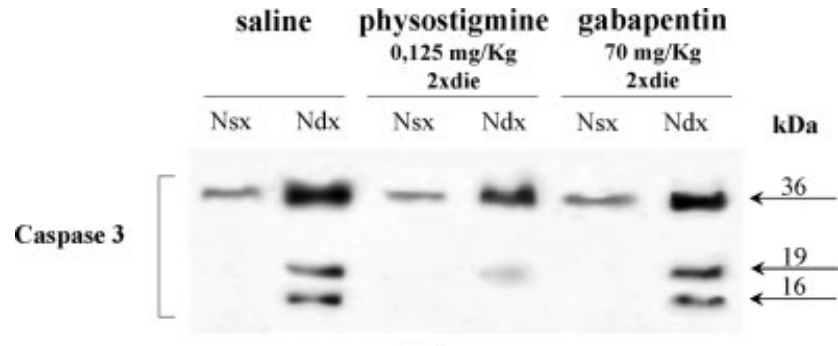

(a)

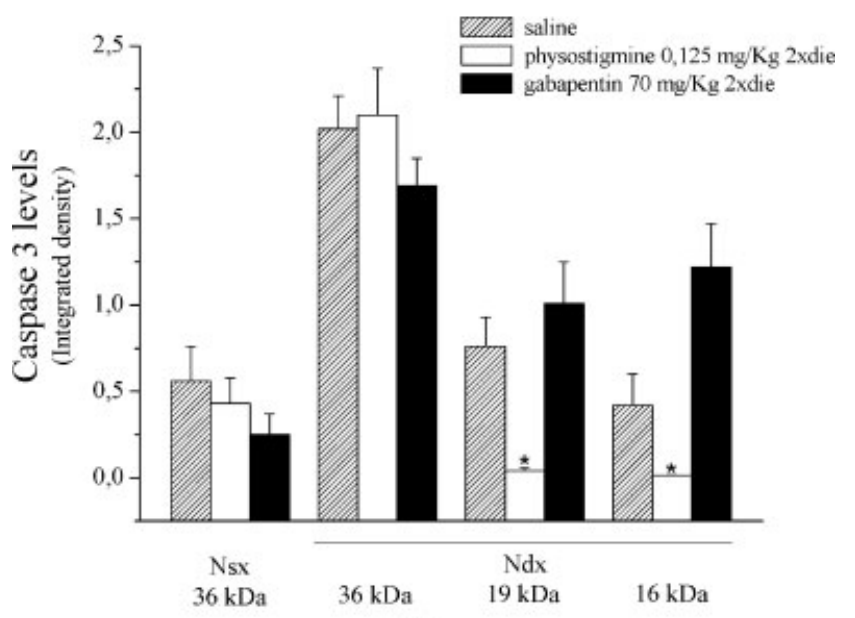

(b)

Fig. 1. Caspase 3 levels. a: Effects of physostigmine and gabapentin treatment on caspase 3 (procaspase $36 \mathrm{kDa}$ and cleavage products 19 and $16 \mathrm{kDa}$ ) expression levels in the ligated right $(\mathrm{Ndx})$ and unoperated left (Nsx) sciatic nerves: comparison with saline treatment. The right nerve $(\mathrm{Ndx})$ was processed with loose ligation, and the administration of substances was performed for 15 days starting on the day of operation. b: Densitometric analysis of Western blot showing the mean \pm SEM from five animals. Each value is expressed as caspaseto- $\beta$-actin level ratio. ${ }^{\star} P<0.01$, significantly different from salinetreated rats.

The protective effect of physostigmine on caspase 3 cleavage was confirmed by the evaluation of the caspase catalytic activity. The cleavage of the specific fluorogenic substrate Z-DEVD-R110 allowed us to observe a threefold increase in caspase 3 activity in the right nerve of saline- and gabapentin-treated groups compared with the physostigmine group, which showed an activity in the right nerve similar to that of the control left nerve (Fig. 2).

Cytochrome $\mathrm{C}$, a mitochondrial intermembrane protein, released following changes in the permeability of the mitochondrial membrane activates caspase 3 . We previously demonstrated that CCI induced a cytochrome C release in the cytosol (Di Cesare Mannelli et al., 2007). In agreement with our previous results, a 14-kDa band, corresponding to cytochrome $\mathrm{C}$, was detected in the purified cytosolic fractions from the right ligated nerve of the saline group (Fig. 3). Repeated administration of physostigmine strongly prevented this effect, whereas gabapentin failed to reduce the cytochrome C 


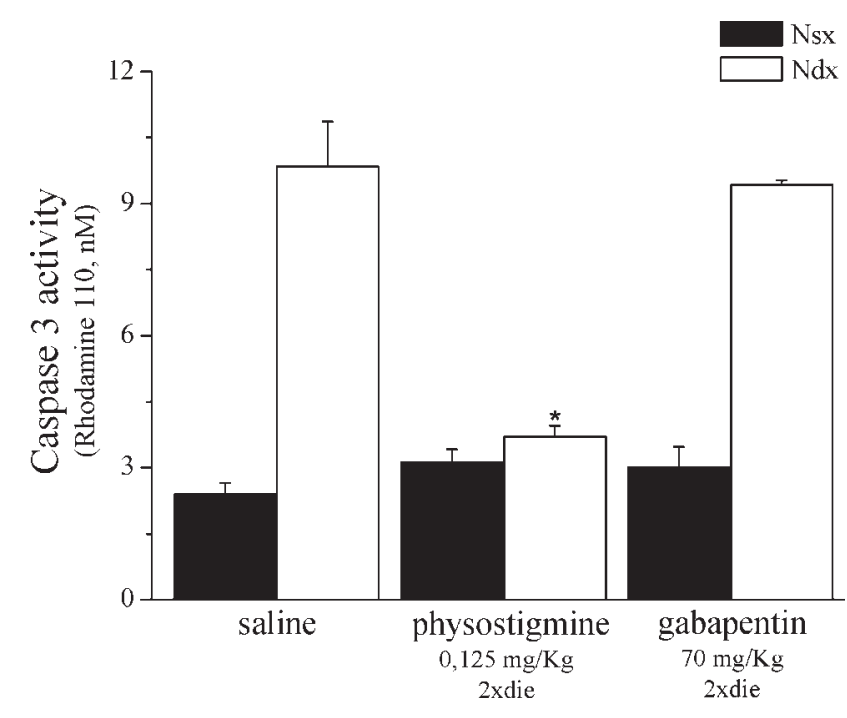

Fig. 2. Caspase 3 activity. a: Catalytic activity was evaluated by measuring the fluorescent compound rhodamine 110 Z-DEVD derivative in nerve homogenate. The CCI effects $(\mathrm{Ndx})$ were evaluated with respect to nonoperated nerve (Nsx) for saline, physostigmine, and gabapentin groups. b: Caspase 3 protease activity express as right-to-left nerve activity ratio. All data are expressed as mean \pm SEM from five animals. $\star P<0.01$, significantly different from saline-treated animals.

level in cytosolic fractions of the right ligated nerve (Fig. 3). Western blot analysis with anti-COX IV, a protein belonging to the inner mitochondrial membrane, was used to confirm separation of mitochondria from the cytosolic fraction (data not shown).

The downstream effects of caspase 3 activation were then evaluated by measuring the expression levels of the $89-\mathrm{kDa}$ fragment of PARP, a $116-\mathrm{kDa}$ protein known to be cleaved by active caspase 3 . Figure 4 shows the expression levels of cleaved PARP in nerves of saline, physostigmine, and gabapentin groups. Only physostigmine prevented PARP cleavage in the right nerve.

Hence, we examined the last event of the programmed cell death cascade, DNA fragmentation. Endonuclease-related gene disruption generates free $3^{\prime}-\mathrm{OH}$ groups at the ends of DNA fragments, which were revealed by colorimetric nick translation labeling technique on $7-\mu \mathrm{m}$ paraffin-embedded tissue. As shown in Figure 5, physostigmine significantly decreased the number of apoptotic nuclei in the right ligated nerve compared with saline-treated animals. The effect of the natural AChE inhibitor is comparable both in the proximal and in the distal region of the nerve. Gabapentin-treated rats were not able to prevent DNA fragmentation after neuropathy induction (Fig. 5).

Finally, to verify whether this physostigmine protective effect was mediated by the IAP (inhibitor of apoptosis proteins) protein family, the levels of XIAP were examined by Western blotting. The treatment with physostigmine up-regulated XIAP, particularly in the right nerve (Fig. 6). On the contrary, XIAP levels after gaba-

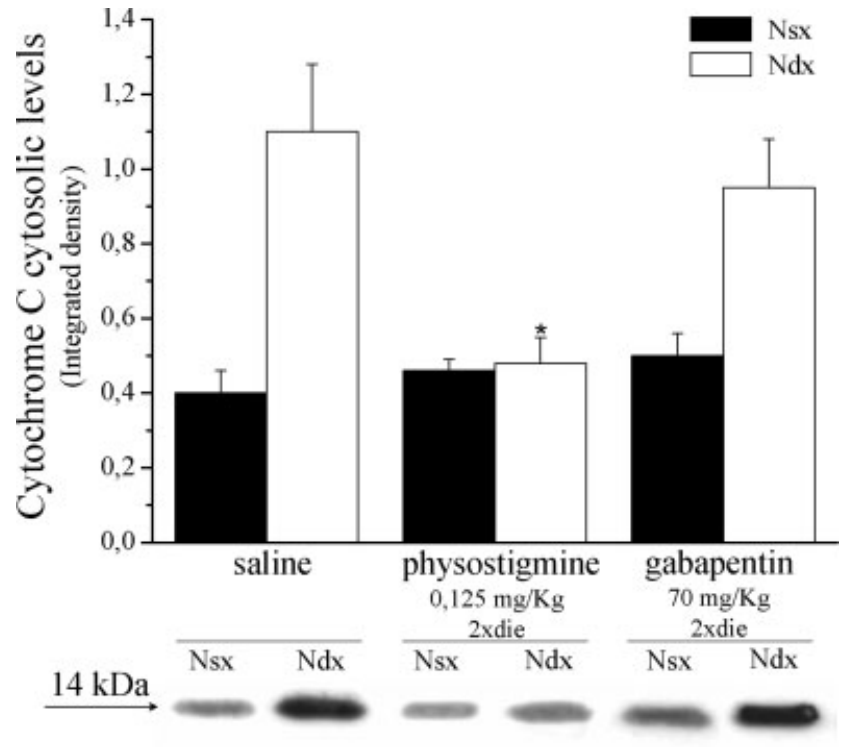

Fig. 3. Cytochrome C cytosolic levels. Cytosolic fraction was extracted and processed by Western blot with specific antibody. ECL detection images and densitometric analysis show the effect obtained by saline, physostigmine, and gabapentin at 15 days treatment $(\mathrm{Ndx})$; for each group, the left nerve (Nsx) was considered as control. Quantitative analysis is reported as mean \pm SEM from five animals. $\star P<0.01$, significantly different from saline-treated rats.

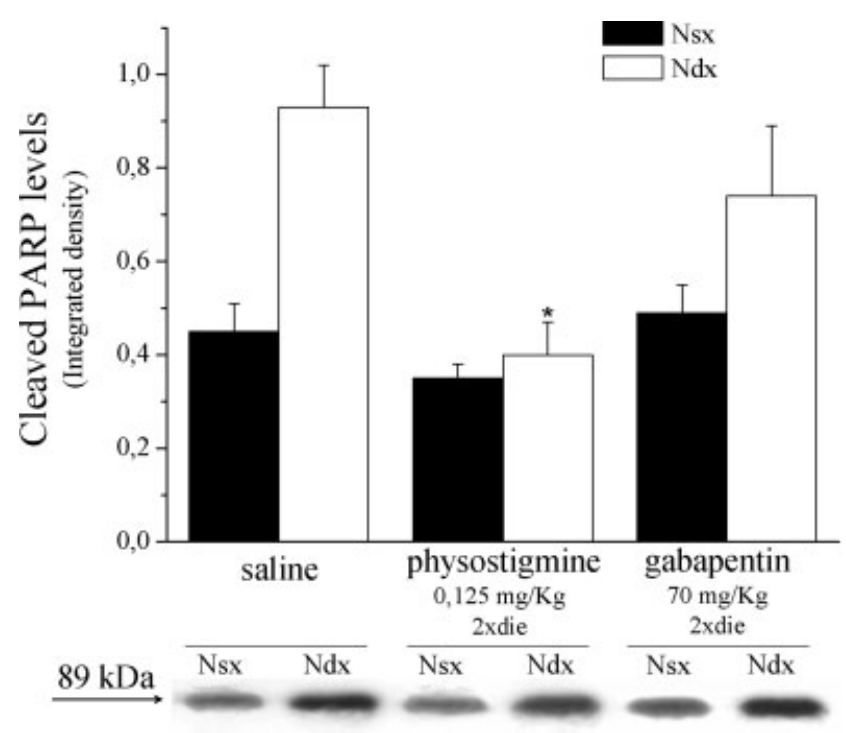

Fig. 4. Cleaved PARP levels. Nerve homogenate evaluation for 89$\mathrm{kDa}$ PARP fragment by immunoblot. Densitometric analysis is performed for each treatment group and expressed as mean \pm SEM from five animals. ${ }^{\star} P<0.01$, significantly different from salinetreated rats.

pentin treatment were analogous in the right and left nerves and were comparable to the levels registered in saline group animals (Fig. 6). 


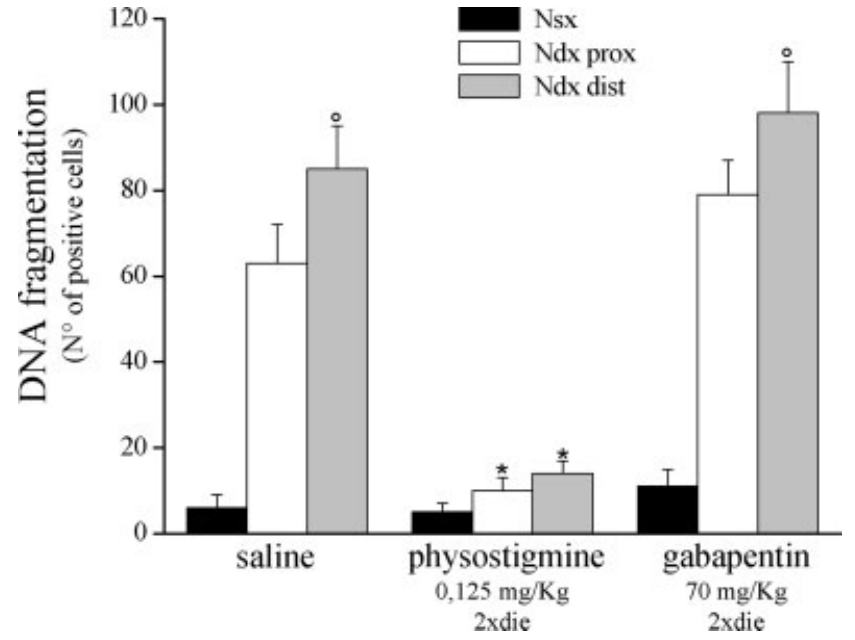

Fig. 5. DNA fragmentation: nick translation labeling. Evaluation of DNA fragmentation on $7-\mu \mathrm{m}$ nerve sections of CCI rats. Positive nuclei number was reported for the left nerve and for the proximal and distal regions of the right nerve, with respect to ligation. Chronic (15 days) saline, physostigmine, and gabapentin administration effects were observed. Quantitative analysis was performed evaluating five animals for each group and analyzing for each nerve six sections and six fields per section. Mean \pm SEM of positive cells is represented. ${ }^{\star} P<0.01$, significantly different from saline-treated rats. ${ }^{\circ} P<0.01$, significantly different from proximal nerve part values.

\section{DISCUSSION}

In mammals, acetylcholinesterase is encoded by a single gene, ACHE, that by an alternative splicing generates three distinct AChE variants, each with a different carboxyterminal sequence: the synaptic, erythrocytic, and readthrough AChE isoforms. The carboxy-terminal sequences determine their homologous assembly into AChE oligomers and their heterologous association with noncatalytic subunits, which direct the subcellular localization of the protein (Soreq and Seidman, 2001). AChE is able to modulate both cell growth and cell death. It is still not known whether the cellular distribution pattern of $\mathrm{AChE}$ is the primary basis for the apoptotic functions of this enzyme. However, specific AChE variants and distributions have been observed in apoptotic cells. Jiang and Zhang (2008) observed that the expression of synaptic AChE was markedly increased in the perinuclear and nuclear regions of apoptotic cells. During the late stages of apoptosis, AChE accumulates inside the apoptotic body with condensed chromatin (Zhang et al., 2002; Yang et al., 2002). Enhanced AChE variant expression may influence the expression of other group genes, including those involved in apoptosis (Ben-Ari et al., 2006). It has been suggested that, in the presence of apoptotic stimuli or under stress conditions, AChE would bind with specific partners or influence other elements. This fact may explain why the overexpression of the synaptic AChE does not initiate but rather enhances the sensitivity to cell death (Jin et al., 2004). AChE also contributes to the formation of the apoptosome during apoptosis (Park et al., 2004).

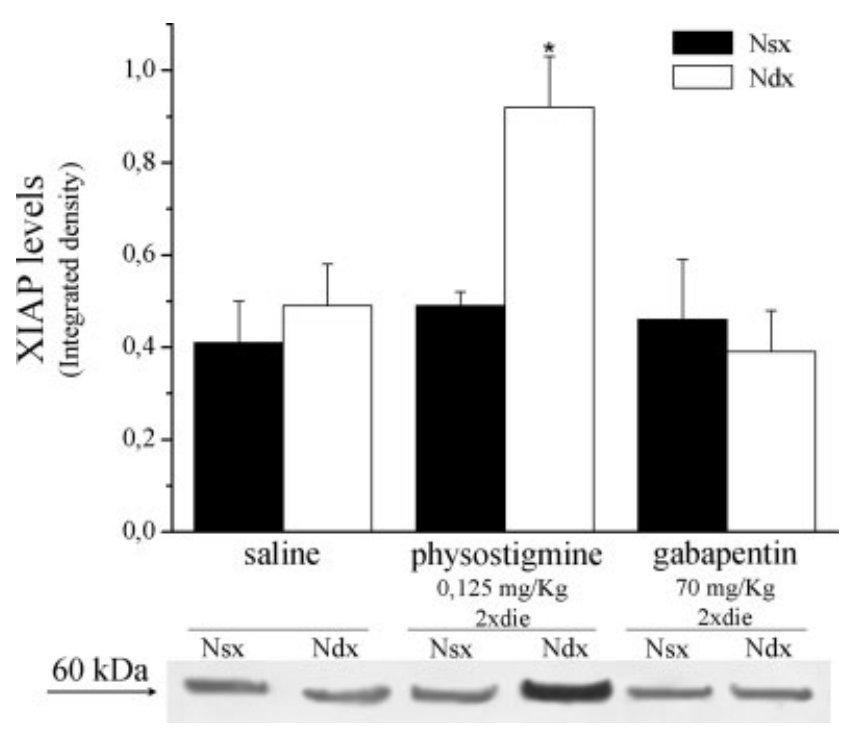

Fig. 6. X-linked inhibitor of apoptosis protein (XIAP) expression levels. Right $(\mathrm{Ndx})$ and left (Nsx) nerves were homogenized and processed by Western blot with specific antibody. ECL detection images and densitometric analysis show the effect obtained with saline, physostigmine, and gabapentin at 15 days treatment. Quantitative analysis is reported as mean \pm SEM from five animals. ${ }^{\star} P<$ 0.01 , significantly different from saline-treated rats.

Physostigmine is an AChE inhibitor originally extracted from calabar beans. It is licensed in many countries as an agent for reversing the effect of drugs and poisons causing the anticholinergic syndrome. In the present work, we show the effect of this natural compound in a model of peripheral neuropathy, a syndrome characterized by nerve damage and nervous tissue degeneration, and the role of apoptosis in tissue alterations and cell loss is widely substantiated (Dalakas et al., 2001; Andre et al., 2002; Moulder et al., 2002; Siler-Marsiglio et al., 2004; Leinninger et al., 2006; Melli et al., 2006; Di Cesare Mannelli et al., 2007).

The present results show that a repeated administration of physostigmine prevents the DNA fragmentation in the nuclei of sciatic nerve Schwann cells. This protection from the latest effect of programmed cell death also involves the upstream events. In fact, repeated treatment with physostigmine decreases the efflux of cytochrome C into the cytosol, leading to a reduction of the cytochrome C level in this cell compartment. Park et al. (2004) demonstrated that silencing AChE with siRNA blocked the interaction between apoptotic protease activating factor 1 and cytochrome C (Park et al., 2004). Our evidence regarding an early protective effect, the release of the cytochrome $\mathrm{C}$ into the cytosol, suggests that physostigmine treatment allows obtaining a dual result: an AChEdependent apoptosis inhibition and a protective effect resulting from increased ACh levels (Kim et al., 2008).

The drastic reduction of both the expression and the catalytic activity of the caspase 3 is in agreement with these results. Moreover, the prevention of forma- 
tion of the $89-\mathrm{kDa}$ PARP cleavage fragment, known to be produced by caspase 3 activity, in the physostigminetreated rats confirms its protective activity. To elucidate the mechanism of physostigmine-mediated apoptosis inhibition, we evaluated XIAP level in our neuropathy model. After 15 days from ligation, physostigmine treatment increased XIAP level in the operated nerve but not in the contralateral one. This difference was not showed in the control group treated with saline solution, suggesting a XIAP role in the antiapoptotic activity of physostigmine. On the other hand, caspase function can be terminated by its removal from the cell using the ubiquitin-targeted proteasome degradation machinery or by a direct inhibition of its enzymatic activity. Salvesen and other authors (Salvesen and Duckett, 2002; Riedl and Shi, 2004; Vaux and Silke, 2005) have reported that members of the inhibitor of apoptosis protein (IAP) family are capable of both functions. In particular, for the most intensively studied family member, XIAP, biochemical and structural studies have precisely mapped the elements of this protein required for caspase inhibition (Eckelman et al., 2006). A direct, XIAP-mediated effect of physostigmine on caspase regulation is an intriguing hypothesis. Neither a protective effect on apoptosis activation nor an XIAP increase was revealed after repeated gabapentin administration at a dose fully active against neuropathic pain. The natural $\mathrm{AChE}$ inhibitor physostigmine protects the sciatic nerve from apoptotic process during neuropathy at the same doses able to reduce hyperalgesia, confirming a link with the antihyperalgesic and antiapoptotic effect as demonstrated for caspase inhibitors (Joseph and Levine, 2004) and for acetyl-L-carnitine (Di Cesare Mannelli et al., 2007).

\section{REFERENCES}

Andre N, Carre M, Brasseur G, Pourroy B, Kovacic H, Briand C, Braguer D. 2002. Paclitaxel targets mitochondria upstream of caspase activation in intact human neuroblastoma cells. FEBS Lett 532:256-260.

Ben-Ari S, Toiber D, Sas AS, Soreq H, Ben-Shaul Y. 2006. Modulated splicing-associated gene expression in P19 cells expressing distinct acetylcholinesterase splice variants. J Neurochem 97:24-34.

Bennett GJ, Xie YK. 1988. A peripheral mononeuropathy in rat that produces disorders of pain sensation like those seen in man. Pain 33:87-107.

Cervia D, Martini D, Garcia-Gil M, Di Giuseppe G, Guella G, Dini F, Bagnoli P. 2006. Cytotoxic effects and apoptotic signalling mechanisms of the sesquiterpenoid euplotin $\mathrm{C}$, a secondary metabolite of the marine ciliate Euplotes crassus, in tumour cells. Apoptosis 115:829-843.

Dalakas MC, Semino-Mora C, Leon-Monzon M. 2001. Mitochondrial alterations with mitochondrial DNA depletion in the nerves of AIDS patients with peripheral neuropathy induced by $2^{\prime} 3^{\prime}$-dideoxycytidine (ddC). Lab Invest 81:1537-1544.

Di Cesare Mannelli L, Ghelardini C, Calvani M, Nicolai R, Mosconi L, Vivoli E, Pacini A, Bartolini A. 2007. Protective effect of acetyl-1-carnitine on the apoptotic pathway of peripheral neuropathy. Eur J Neurosci 26:820-827.

Eckelman BP, Salvesen GS, Scott FL. 2006. Human inhibitor of apoptosis proteins: why XIAP is the black sheep of the family. EMBO Rep 7:988-994.

Finnerup NB, Sindrup SH, Jensen TS. 2007. Chronic neuropathic pain: mechanisms, drug targets and measurement. Fundam Clin Pharmacol 21:129-136
Galeotti N, Bartolini A, Ghelardini C. 2003. The phospholipase C-IP3 pathway is involved in muscarinic antinociception. Neuropsychopharmacology 28:888-897.

Gorczyca W, Gong J, Darzynkiewicz Z. 1993. Detection of DNA strand breaks in individual apoptotic cells by the in situ terminal deoxynucleotidyl transferase and nick translation assays. Cancer Res 53:1945-1951.

Huang X, Lee B, Johnson G, Naleway J, Guzikowski A, Dai W, Darzynkiewicz Z. 2005. Novel assay utilizing fluorochrome-tagged physostigmine $(\mathrm{Ph}-\mathrm{F})$ to in situ detect active acetylcholinesterase (AChE) induced during apoptosis. Cell Cycle 4:140-147.

Hughes RAC. 2002. Peripheral neuropathy. Br Med J 324:466-469.

Jensen TS, Gottrup H, Sindrup SH, Bach FW. 2001. The clinical picture of neuropathic pain. Eur J Pharmacol 429:1-11.

Jiang H, Zhang XJ. 2008. Acetylcholinesterase and apoptosis: a novel perspective for an old enzyme. FEBS J 275:612-617.

Jin QH, He HY, Shi YF, Lu H, Zhang XJ. 2004. Overexpression of acetylcholinesterase inhibited cell proliferation and promoted apoptosis in NRK cells. Acta Pharmacol Sin 25:1013-1021.

Joseph EK, Levine LD. 2004. Caspase signaling in neuropathic and inflammatory pain in the rat. Eur J Neurosci 20:2896-2902.

Kim MH, Kim MO, Heo JS, Kim JS, Han HJ. 2008. Acetylcholine inhibits long-term hypoxia-induced apoptosis by suppressing the oxidative stress-mediated MAPKs activation as well as regulation of Bcl-2, c-IAPs, and caspase-3 in mouse embryonic stem cells. Apoptosis 13: 295-304

Leinninger GM, Edwards JL, Lipshaw MJ, Feldman EL. 2006. Mechanisms of disease: mitochondria as new therapeutic targets in diabetic neuropathy. Nat Clin Pract Neurol 2:620-628.

Melli G, Keswani SC, Fischer A, Chen W, Hoke A. 2006. Spatially distinct and functionally independent mechanisms of axonal degeneration in a model of HIV-associated sensory neuropathy. Brain 129:1330-1338.

Moulder KL, Fu T, Melbostad H, Cormier RJ, Isenberg KE, Zorumski CF, Mennerick S. 2002. Ethanol-induced death of postnatal hippocampal neurons. Neurobiol Dis 10:396-409.

Obrosova IG, Van Huysen C, Fathallah L, Cao XC, Greene DA, Stevens MJ. 2002. An aldose reductase inhibitor reverses early diabetes-induced changes in peripheral nerve function, metabolism, and antioxidative defense. FSSEB J 16:123-125.

Park SE, Kim ND, Yoo YH. 2004. Acetylcholinesterase plays a pivotal role in apoptosome formation. Cancer Res 64:2652-2655.

Pöyhiä R, Xu M, Kontinen VK, Paananen S, Kalso E. 1999. Systemic physostigmine shows antiallodynic effects in neuropathic rats. Anesth Analg 89:428-433.

Riedl SJ, Shi Y. 2004. Molecular mechanisms of caspase regulation during apoptosis. Nat Rev Mol Cell Biol 5:897-907.

Salvesen GS, Duckett CS. 2002. IAP proteins: blocking the road to death's door. Nat Rev Mol Cell Biol 3:401-410.

Siler-Marsiglio KI, Shaw G, Heaton MB. 2004. Pycnogenol and vitamin E inhibit ethanol-induced apoptosis in rat cerebellar granule cells. J Neurobiol 59:261-271.

Soreq H, Seidman S. 2001. Acetylcholinesterase-new roles for an old actor. Nat Rev Neurosci 2:294-302.

Vaux DL, Silke J. 2005. IAPs, RINGs and ubiquitylation. Nat Rev Mol Cell Biol 6:287-297.

Villaroya M, Garcia AG, Marco-Contelles J, Lopez MG. 2007. An update on the pharmacology of galantamine. Expert Opin Invest Drugs 16:1987-1998.

Yang L, He HY, Zhang XJ. 2002. Increased expression of intranuclear AChE involved in apoptosis of SK-N-SH cells. Neurosci Res 42:261268.

Zhang XJ, Yang L, Zhao Q, Caen JP, He HY, Jin QH, Guo LH, Alemany M, Zhang LY, Shi YF. 2002. Induction of acetylcholinesterase expression during apoptosis in various cell types. Cell Death Differ 9:790-800. 